INF. \& ANN.

\title{
Forty Seventh Refresher Course in Experimental Physics
}

\author{
Sponsored by \\ March 5 to 20, 2013 \\ Indian Academy of Sciences, Bangalore \\ Indian National Science Academy, New Delhi \\ The National Academy of Sciences, India, Allahabad
}

This Forty Seventh Course will be held at its premises in Bangalore. Participants in this course will gain hands-on experience with about 25 experiments, some at the BSc level and some at the MSc level with a low cost kit developed for the Indian Academy of Sciences, Bangalore, and manufactured by Ajay Sensors and Instruments, Bangalore. Some advanced experiments in tracing phase transitions and in low temperature physics will also be included.

Refresher Courses in Experimental Physics held so far have been highly successful and the experiments have been included in the curricula of several universities in the South. Over one hundred kits have been sold and are used in universities and other high level institutions like the Centre for Excellence in Basic Sciences of the University of Mumbai and TIFR.

The total number of seats in the Course will be about 25; while the course is essentially meant for teachers in universities and colleges, a few seats will be available for students of III BSc and I MSc Physics courses.

Interested applicants must send their detailed bio-data including name, gender, date of birth, educational qualifications, office address, mobile telephone number, e-mail address, a statement as to why they would like to attend the course and its usefulness to their career, and (in the case of faculty) teaching and research experience and a list of published papers if any. The application should be sent to: Sri G Madhavan, Coordinator, Science Education Programme, Indian Academy of Sciences, CV Raman Avenue, Sadashivanagar, Bangalore 560080.

Email: madhavan@ias.ernet.in

In the case of teacher applicants, the application should be forwarded by the Head of the Institution stating that leave will be sanctioned if the applicant is selected for the course. Selected participants will be intimated by email by early December 2012 .

Selected participants will be paid the actual to and fro railway fare not exceeding three-tier AC fare. Boarding and lodging in Bangalore will be taken care of by the Academy. It has been bought to our attention that teachers in Universities/Colleges who attend Refresher Courses of two-week duration are also entitled to be considered for promotion.

Last date for receiving applications will be 30 November 2012.

RESONANCE | November 2012 